\title{
BCG immunisation in England and Wales: a survey of policy and practice in schoolchildren and neonates
}

\author{
Carol A Joseph, John M Watson, Kate J Fern
}

\begin{abstract}
Objective-To determine the policy and practice of district health authorities in England and Wales for BCG immunisation in schoolchildren and neonates.

Design-Self completion postal questionnaire survey.

Participants-District immunisation coordinators.

Setting - 199 district health authorities in England and Wales.

Results-Questionnaires were received from 186 districts, a response rate of $94 \%$. Considerable uniformity was observed in many aspects of BCG immunisation policy and practice but some important variations were found. 15 districts no longer carry out a routine schools programme. 148 districts offer BCG to selected groups of neonates and five to all neonates, but 31 districts do not offer BCG to this age group. The recommended action in response to different levels of tuberculin sensitivity in schoolchildren and neonates varied among districts.

Conclusions-Despite the recommendations of the Joint Committee on Vaccination and Immunisation some districts do not offer BCG immunisation to neonates at high risk of tuberculosis and there are important variations in other aspects of BCG policy.
\end{abstract}

\section{Introduction}

Although the overall number of tuberculosis notifications has remained about the same since the mid1980 s, ${ }^{1}$ the overall incidence of tuberculosis has been declining in England and Wales for at least 100 years. Specific chemotherapy since the 1940s and BCG immunisation of schoolchildren since the 1950s and, more recently, of neonates in high risk groups may have contributed to the decline in recent decades. As the incidence of disease has dropped to low levels, so the potential for preventing new cases of tuberculosis by the schools BCG immunisation programme has diminished. ${ }^{3}$ In addition, giving BCG vaccine to neonates in high risk groups means that many of the most vulnerable children are already protected by the time they are eligible for the schools programme. ${ }^{4}$

In 1983 a survey of BCG immunisation policies for schoolchildren and neonates in health districts of England and Wales revealed that five health authorities had discontinued their schools programme and a further 10 had their policy under review. ${ }^{5}$ The national survey of notifications of tuberculosis, also in 1983, confirmed the continuing fall in notification rates in the white population. ${ }^{6}$ Similar rates of decline were also seen in people originating from the Indian subcontinent, but the rates in this group were still 20-30 times higher than those in the indigenous population. After reviewing these data in 1985 the Joint Committee on Vaccination and Immunisation recommended the continuation of the schools programme, with the intention of stopping by 1990 provided that a further notification survey showed that the downward trend in notifications was maintained. ${ }^{7}$ Despite a continuing decline in the age and sex specific incidence of tuberculosis up to 1987 , small increases in the total number of notifications were observed in 1988 and $1989 .{ }^{8}$ In 1990 the committee reviewed the situation and, largely because of uncertainties about the effect of the interaction between HIV and tuberculosis, recommended that the schools BCG programme be continued for at least another five years, when the results of a further notification survey in 1993 would be available.'

A relocation of the site of vaccine production interrupted the supplies of BCG vaccine to schools in England and Wales in 1989/90. ${ }^{10} 11$ In addition, the Public Health Laboratory Service Communicable Disease Surveillance Centre and the Department of Health had both received inquiries about alternative methods for tuberculin testing and giving BCG vaccine to certain groups. In the light of these changing circumstances it was considered timely to repeat the survey of BCG policies and practice in England and Wales.

\section{Methods}

A postal questionnaire inquiring into the policy and practice of BCG immunisation for schoolchildren and neonates was sent to the district immunisation coordinators of 199 district health authorities in England and Wales in June 1991. A covering letter requested that, where appropriate, relevant information be obtained from those involved in the schools programme and from those involved in giving BCG to neonates. A follow up letter and a further questionnaire were sent to non-responding districts after four weeks, followed by reminder telephone calls to those that failed to return their questionnaires two months after the start of the survey.

Responders were asked to estimate, within specified ranges, the percentage of the population of their health district that was of Indian subcontinent ethnic origin in 1990. This information was subsequently validated with unpublished data on the number of births to mothers born in the Indian subcontinent as a proportion of the total number of births within each health district (Office of Population Censuses and Surveys, personal communication) and was used for comparison with reported district policy for BCG immunisation.

Questionnaire data were entered on to a computer, verified, and analysed with Epi Info software. ${ }^{12}$ After preliminary analysis, districts returning incomplete questionnaires or contradictory information were contacted by telephone to clarify their responses.

\section{Results}

A total of 186 (94\%) questionnaires were returned from 199 district health authorities in England and 
Wales. Two districts had merged and returned only one questionnaire, and a further two questionnaires were excluded because they arrived after completion of the data analysis. Thus subsequent analyses are based on returns from 184 districts.

\section{SCHOOLS PROGRAMME}

One hundred and sixty nine (92\%) districts were carrying out routine BCG immunisation in schoolchildren aged 10-14 years. The remaining $15(8 \%)$ stopped their programmes between 1976 and 1990 . Nine of these districts were located in the adjacent regional health authorities of Oxford, Wessex, South Western, and West Midlands. No district intends to stop its programme in the near future, but 13 have their policies under review. Fourteen districts gave a low incidence of tuberculosis locally as their reason for stopping their schools programme; seven cited concern about the side effects of the vaccine, and four cited cost. Only one district cited interruption to the vaccine supply in 1989 . No district with a population of Indian subcontinent origin estimated at greater than $5 \%$ had stopped their schools programme, although the programme had been stopped in three districts with an estimated population of 3-5\%.

Eighteen districts offered selective BCG immunisation to groups of children at school entry, including 15 specifying immunisation of children who had recently immigrated. Selective immunisation at school entry was more common in districts with large populations from the Indian subcontinent but was offered in only two of the 15 districts where the routine schools programme had been stopped.

\section{Tuberculin testing}

One hundred and sixty districts (95\%) used the Heaf multiple puncture tuberculin test, five used the Tine test, and four the Mantoux test. Of those using the Heaf test, $129(81 \%)$ used the fixed head multiple use sterilisable Heaf gun and a further 20 used apparatus with a detachable head. The Heaf test reaction was read at seven days in $128(80 \%)$ districts but at only three days in seven (6\%). The Mantoux and Tine test reactions were generally read at three days. Unusual reactions to the tuberculin test during the academic year 1990-1 were reported from 27 districts. Eight districts reported children with abscesses or other severe local reactions, four reported children with localised erythema, and two reported episodes of anaphylaxis.

There was general agreement among the 165 districts using the Heaf or Tine tests about the action to take with grade 0,3 , or 4 results in children with no history of BCG immunisation - that is, immunisation for grade 0 and clinic referral for grades 3 and 4 (table I). With a grade 1 result, 149/165 (90\%) recommended immunisation, whereas nine $(5 \%)$ recommended no action. With a grade 2 result, one district recommended immunisation, 57 (35\%) no action, and 97 $(57 \%)$ clinic referral. In children with evidence of a previous BCG immunisation there were variations in the recommended action at all grades of result. Thirteen districts reported positive (grade 2 or more)

TABLE I - Number (percentage) of district health authorities recommending action for each grade of result of Heaf or Tine tuberculin test in schoolchildren

\begin{tabular}{|c|c|c|c|c|c|c|c|c|}
\hline \multirow[b]{2}{*}{ Grade } & \multicolumn{4}{|c|}{ No previous history of BCG immunisation } & \multicolumn{4}{|c|}{ Evidence of previous BCG immunisation } \\
\hline & Immunisation & $\begin{array}{c}\text { No } \\
\text { action }\end{array}$ & $\begin{array}{l}\text { Clinic } \\
\text { referral }\end{array}$ & $\begin{array}{c}\text { Not } \\
\text { known }\end{array}$ & Immunisation & $\begin{array}{c}\text { No } \\
\text { action }\end{array}$ & $\begin{array}{l}\text { Clinic } \\
\text { referral }\end{array}$ & $\begin{array}{c}\text { Not } \\
\text { known }\end{array}$ \\
\hline 0 & $163(99)$ & & & $2(1)$ & $91(55)$ & $58(35)$ & $1(<1)$ & $15(9)$ \\
\hline 1 & $149(90)$ & $9(5)$ & & $7(5)$ & $37(22)$ & $111(67)$ & $1(<1)$ & $16(10)$ \\
\hline 2 & $1(<1)$ & $57(35)$ & $97(57)$ & $10(7)$ & & $144(87)$ & $10(6)$ & $11(7)$ \\
\hline 3 & & & $163(99)$ & $2(1)$ & & $44(27)$ & $110(66)$ & $11(7)$ \\
\hline 4 & & & $164(99)$ & $3(1)$ & & $31(19)$ & $124(75)$ & $10(6)$ \\
\hline
\end{tabular}

tuberculin test results in greater than $10 \%$ of unvaccinated children during the previous school year.

Districts were asked what they would accept as satisfactory evidence of a previous BCG immunisation. Combinations of scar with parental testimony or documentary evidence were accepted as evidence in 155 (92\%) districts. Scar alone was accepted by 102 $(60 \%)$ districts, documentary evidence alone by 81 $(48 \%)$, and parental testimony alone by $30(18 \%)$.

\section{Administration of $B C G$ vaccine}

One hundred and sixty three of the 169 districts carrying out the schools BCG programme gave BCG intradermally with needle and syringe, three used percutaneous multiple puncture with a modified Heaf gun, and one used a jet injector. In 28 districts the vaccination lesion was inspected routinely, in 21 at 5-12 weeks after immunisation. One district reported that $1 \%$ and another that $3 \%$ of their schoolchildren had large ulcers or abscesses after BCG immunisation.

\section{PROGRAMME FOR NEONATES}

Only five districts routinely offered BCG vaccine to all newborn children and 31 districts offered it to none. However, $148(80 \%)$ districts, including 14 of the 15 districts that had stopped the schools programme, offered BCG vaccine to selected groups of neonates: babies from ethnic minority groups from the Indian subcontinent, Africa, the West Indies, China, the Middle East, and South East Asia. In addition, 120 districts reported that they offered the vaccine to the newborn children of recent immigrants from other countries with a high incidence of tuberculosis. Forty one districts offered it to neonates with a family history of the disease, and seven districts offer BCG vaccine to neonates from socially deprived indigenous white households.

In four of the five districts that offered BCG vaccine to all their neonates the population of Indian subcontinent origin was greater than $10 \%$, and in the fifth between $3 \%$ and $5 \%$. Eight of the 31 districts not offering BCG immunisation to any newborn group had Indian subcontinent populations of $3 \%$ or greater, and one of these estimated this population to be between $11 \%$ and $20 \%$.

Of the 153 districts that offered BCG vaccine to neonates, $103(67 \%)$ routinely gave it within the firs six days of life, 18 between 1-4 weeks, 21 during the second month of life, and one in the third month. Two districts gave the vaccine at the same time as the first routine diphtheria, tetanus, pertussis, and polio immunisation at 2 months. Immunisation was mos commonly carried out in the postnatal ward, followed by the child health clinic, chest clinic, or at home by a health visitor or nurse.

\section{Tuberculin testing}

Districts were asked the maximum age at which they would give BCG vaccine without a prior tuberculin test. They reported a range of 1 week to 1 year (mean 8.5 weeks); most districts $(113,74 \%)$ were within the range of 1-12 weeks. Tuberculin testing of infants, when appropriate, was carried out in 36 districts with the Heaf test, in 11 with the Mantoux test, and in seven with the Tine test. No unusual reactions to tuberculin testing in this group were reported.

Among the 42 districts responding to the question that had a policy for tuberculin testing and BCG immunisation in infants, nine $(21 \%)$ were unsure of the action taken locally in response to the different test results. Of the remainder, $21(50 \%)$ recommended vaccination of those with a grade 1 result and four (10\%) districts recommended no action for a grade 2 
result. All districts recommended clinic referral for grade 3 and 4 results (table II).

TABLE II -Number (percentage) of district health authorities recommending action for each grade of result of Heaf of Tine tuberculin test in neonates

\begin{tabular}{ccccc}
\hline Grade & Immunisation & No action & Clinic referral & Not known \\
\hline 0 & $33(79)$ & & & $9(21)$ \\
1 & $21(50)$ & & $13(31)$ & $8(19)$ \\
2 & & $4(10)$ & $30(71)$ & $8(19)$ \\
3 and 4 & & & $34(81)$ & $8(19)$ \\
\hline
\end{tabular}

\section{Administration of $B C G$ vaccine}

In 153 districts where BCG vaccine was given to neonates it was given intradermally with needle and syringe, but in seven districts percutaneous multiple puncture with a modified Heaf gun was carried out. No severe reactions to the vaccine were reported.

\section{DISTRICT POLICY MAKERS}

Districts were asked who was involved in or consulted about the health authority's policy on the BCG schools programme and the programme for neonates. The director of public health, the consultant in communicable disease control, or the district immunisation coordinator were most frequently involved in both programmes, with chest physicians consulted in $74 \%$ of schools programmes and paediatricians in $88 \%$ of programmes for neonates (table III). Either an immunisation committee or a control of infection committee was usually consulted about the schools programme, but in 27 districts neither type of committee was consulted about the programme for neonates.

TABLE III-Number of districts with staff involved in or consulted about policy for BCG immunisation programmes

\begin{tabular}{lcc} 
District staff & $\begin{array}{c}\text { Schools } \\
\text { programme }\end{array}$ & $\begin{array}{c}\text { Programme } \\
\text { for neonates }\end{array}$ \\
\hline $\begin{array}{l}\text { Director of public health or consultant in } \\
\quad \text { communicable disease control }\end{array}$ & 158 & 128 \\
Immunisation coordinator & 154 & 118 \\
Chest physician or other physician & 124 & 107 \\
Paediatrician & 102 & 135 \\
Immunisation committee or control of & 130 & 94 \\
$\quad$ infection committee & & \\
\hline
\end{tabular}

\section{Discussion}

This survey has shown important variations in current policies and practice for BCG immunisation of schoolchildren and neonates in health districts in England and Wales. In particular, it is of concern that 15 districts have stopped their schools programme and 31 have no policy for immunisation of neonates.

The routine schools programmes had been stopped by 1983 in five districts, but in one of these the cessation was only temporary and the programme was subsequently restarted. Since then 11 more districts have discontinued their schools programme and 13 have their policy under review. However, none of the 10 districts that had their policy under review in 1983 had withdrawn their schools programme by 1991 .

Contrary to expectations, the interruption in the supply of BCG vaccine in 1989 was not an important factor in stopping the schools programme; the stoppage was most often related to the low incidence of tuberculosis locally. Districts not offering a schools programme were most often located in central and south western England and had populations with a low proportion of residents of Indian subcontinent origin. One district that discontinued its schools programme in 1981 concluded that the change in immunisation policy did not affect the continuation of its annual decline in notifications, although follow up was only of cases and deaths notified from that region and did not include cases that might have been notified elsewhere. ${ }^{13}$

The Heaf tuberculin test remains the most used of the available methods and seems to be associated with few problems. A new gun with a disposable magnetic head, which has been developed under the guidance of the Department of Health, is now available for general use and will make the use of the Heaf test easier and avoid any risk of cross infection.

\section{ACTION ON TEST RESULTS}

The variation in the actions carried out in response to tuberculin test results in school children indicates the lack of clarity in published guidance. Ninety seven districts $(57 \%)$ recommend that children with a grade 2 result and with no history of BCG immunisation be referred to a chest clinic. As a result, however, of the low true prevalence of this infection in schoolchildren in Britain and the limitations to the validity of any form of screening tuberculin test, false positives are highly likely and important clinical findings are rarely encountered on follow up of this group. The BCG subcommittee of the Joint Committee on Vaccination and Immunisation has recently considered this issue and recommended that clinic referral for this group is not necessary..$^{14}$

In children previously immunised with BCG, 10 districts $(6 \%)$ recommended that those with grade 2 results still needed referral to a chest clinic, despite the fact that this level of tuberculin sensitivity is entirely consistent with their previous BCG immunisation. Referral of this group is not necessary.

A total of 128 districts $(77 \%)$ recommended that previously immunised children with grade 0 or grade 1 results be immunised again. This too may be unnecessary. The Joint Committee on Vaccination and Immunisation has recommended that children with convincing evidence of previous immunisation should not be reimmunised. ${ }^{14}$ There are variations in what is accepted as evidence of previous immunisation, and it would seem prudent to accept an appropriately located, characteristic scar with or without documentary evidence. In 44 districts (27\%) previously immunised children with grade 3 or grade 4 results were not recommended for follow up, although such strongly positive results are more than would be expected from previous BCG immunisation. This group should be referred.

For neonates there has been an encouraging increase in the number of districts offering selective immunisation. However, it is of concern that 31 districts do not offer BCG to any group of newborn children, particularly as eight of these districts estimated that they had populations of Indian subcontinent origin greater than 3\%. BCG immunisation of neonates has been shown to be effective in protecting children of Indian subcontinent origin against tuberculosis in England. ${ }^{15-17}$

A recent study from Leeds suggested that poverty, as indicated by residence in a "designated urban priority area," was an important indicator of the risk of tuberculosis in children. The study's authors advocated that selective BCG policies for neonates should not depend on ethnic group alone,$^{18}$ and it is interesting to note that seven districts stated that they offer BCG immunisation to newborn children from "socially deprived indigenous white households."

\section{ADMINISTRATION OF THE VACCINE}

BCG and other live vaccines, including oral polio vaccine, may be given at the same time. This should be made clear in those districts wishing to offer selective newborn immunisation but not wishing to carry this out in hospital in the few days after birth: so that this immunisation can be given at the same time as the 
routine childhood immunisations at 2 months and neither BCG nor the beginning of the childhood course is postponed.

Information is not available on the age up to which it is safe to give BCG immunisation without a prior tuberculin test. The Joint Committee on Vaccination and Immunisation has agreed, however, that in the absence of any suggestion of recent contact with tuberculosis a cut off point at 3 months would be sensible. ${ }^{1+}$ The committee also advised that vaccination by the percutaneous multiple puncture technique, using 18-20 needles, is an acceptable alternative to the intradermal technique in infants and neonates. An instrument with an 18 needle magnetic disposable head is now available and convenient to use.

Tuberculin testing of neonates is less common than testing of schoolchildren, but it is surprising that in five districts no action was recommended for grade 2 results in this age group. Indeed in neonates even a grade 1 result should be considered with suspicion, especially if there is any recent history of contact with tuberculosis.

Whoever takes the leading role in devising a district's policy for BCG immunisation, it is appropriate that the consultant in communicable disease control (or other public health physician, if a consultant is not in post) as well as the district immunisation coordinator consult with a chest physician (or physician with an interest in respiratory medicine) about the policy for the schools programme and with a paediatrician on the policy for the programme in neonates. In addition, it would seem prudent to have such policies reviewed by either a district control of infection committee or an immunisation committee.

We thank Mrs M Bezzant for her administrative support, Ms F Majid for her statistical advice, and Drs K Citron,
J Leese, and C Skinner for their helpful comments on this manuscript. We are also grateful to all the immunisation coordinators, consultants in communicable disease control, and others who provided the information for this national survey. 1 Office of Population Censuses and Survevs. Communicable disease statistics.
London: HMSO, 1974-89. (Series MB2.)

2 Registrar General. Annual report. London: HMSO, 1927-73.

3 Sutherland I, Springett VH. The effects of the scheme for BCG vaccination of schoolchildren in England and Wales and the consequences of discontinuing the scheme at various dates. I Epidemiol Community Health 1989;43:15-24

4 Springett VH, Sutherland I. BCG vaccination of schoolchildren in England and Wales. Thorax 1990;45:83-8.

5 Miller C, Morris J, Pollock TM. PHLS inquiry into current BCG vaccination policy. BMF 1984;288:564.

6 Medical Research Council Tuberculosis and Chest Diseases Unit. National survey of notifications of tuberculosis in England and Wales in 1983. BMF 1985;291:658-61.

7 Department of Health. The school BCG vaccination programme. London: Department of Health and Social Security, 1985. (DA(85)27.)

8 Watson JM, Fern KJ, Porter JDH, Whitmore SE. Notifications of tuberculosis in England and Wales, 1982-89. Communicable Disease Report 1991;1:R13-6.

9 Citron KM. BCG vaccination in children. BMf 1990;301:1275

10 Department of Health. BCG immunisation programme: vaccine supply. London: Department of Health, 1989. (Executive Letter (89)93.)

11 Department of Health. BCG immunisation programme: vaccine supply. London: Department of Health 1990. (Executive Letter (90)P/61.

12 Dean AD, Dean JA, Burton JH, Dicker RC. Epi Info, version 5: a word processing, database and statistics program for epidemiology on microcomputers. Atlanta, Georgia: Centers for Disease Control, 1990.

13 Frankenberg RA, Mayon-White RT. The effect of a policy of non-vaccination of schoolchildren on the incidence of tuberculosis in Oxfordshire. of schoolchildren on the incidence

14 Department of Health, Welsh Office, and Scottish Home and Health Department. Immunisation against infectious disease. London: HMSO (in
Depalth press).

15 Rodrigues LC, Gill ON, Smith PG. BCG vaccination in the first year of life protects children of Indian subcontinent ethnic origin against tuberculosis in England. I Epidemiol Community Health 1991;45:78-80.

16 Packe GE, Innes JA. Protective effect of BCG vaccination in infant Asians: a case-control study. Arch Dis Child 1988;63:277-81.

17 Curtis HM, Leck I, Bamford FN. Incidence of childhood tuberculosis after neonatal BCG vaccination. Lancet 1984:i: 145-8.

18 Cundall DB, Pearson SB. Inner city tuberculosis and immunisation policy. Arch Dis Child 1988;63:964-6.

(Accepted 19 June 1992)

\section{Centre National de}

Transfusion Sanguine, Abidjan, Côte d'Ivoire Dominic Savarit, senior medical technologist Richard Schutz, medical officer

Seydou Konate, medical officer

Alain Bondurand, director

National Center for Infectious Diseases, Centers for Disease Control, Atlanta, Georgia, USA

Kevin M De Cock, international activity, division of HIVIAIDS

Eve Lackritz, malaria branch, division of parasitic diseases

Correspondence to: Dr K M De Cock, Projet RETRO-CI, 01 BP 1712, Abidjan, Côte d'Ivoire, West Africa.

BMJ 1992;305:498-501

\title{
Risk of HIV infection from transfusion with blood negative for HIV antibody in a west African city
}

\author{
Dominic Savarit, Kevin M De Cock, Richard Schutz, Seydou Konate, Eve Lackritz, \\ Alain Bondurand
}

\section{Abstract}

Objective-To estimate the risk of infection with HIV (HIV 1 or HIV 2, or both) from transfusion of a screened unit of blood in a high prevalence area in west Africa.

Design-Retrospective cohort study for JanuaryJuly 1991.

Setting-National Blood Transfusion Centre, Abidjan, Côte d'Ivoire.

Subjects - Repeat donors (5831 units of blood) and first time donors (5076 units) in the first five months of 1991 .

Main outcome measures-Prevalence and estimated incidence of HIV infection in repeat and first time donors; estimated rate of potentially infected, HIV antibody negative units; and rate of (false negative) potentially infected units assuming a laboratory test sensitivity of $\mathbf{9 9 \%}$.

Results-Overall HIV prevalence was $11.0 \%$ in first time donors and $2 \cdot 1 \%$ in repeat donors. In the first seven months of 1991, $29 \mathrm{HIV}$ antibody positive (27 HIV 1, 1 HIV 2, 1 dually reactive) donors with a seronegative unit of blood earlier in the year were identified; 26 had donated blood eight weeks or less before their estimated dates of seroconversion and may have been infectious (minimum rate 26/5831
(4.5/1000 potentially infected units)). Estimated incidence of infection in repeat donors was $1 \cdot 2-2 \cdot 5 \%$. Laboratory test insensitivity would result in an estimated 1.1/1000 false negative units from first time donors and $0 \cdot 2 / 1000$ units from regular donors. The overall rate of potentially infected units (all donors, seroconversions, and errors) was estimated at 5.4-10.6/1000.

Conclusions-The risk of HIV infection from a single unit of blood remains substantial $(5 \cdot 4-10 \cdot 6 /$ 1000 units). To prevent infection from blood transfusion in areas of high incidence and prevalence of HIV all but absolutely essential transfusions should be avoided, and donors with low incidence of HIV infection should be selected.

\section{Introduction}

Measures introduced in the industrialised world to prevent transmission of HIV infection by blood transfusions include adherence to more stringent criteria for the use of blood, use of only voluntarily donated blood, exclusion of high risk donors, and universal testing of donated blood for HIV antibodies.' Despite these measures it is estimated that 1 in every $40000-153000$ units of blood transfused in the United States may be 